\title{
Trends in nosocomial bloodstream infections following health care restructuring in Alberta between 1999 and 2005
}

\author{
Mao-Cheng Lee MD FRCPC ${ }^{1}$, Lynora Saxinger MD FRCPC ${ }^{1}$, Sarah E Forgie MD FRCPC ${ }^{2}$, Geoffrey Taylor MD FRCPC ${ }^{1}$
}

M-C Lee, L Saxinger, S Forgie, G Taylor. Trends in nosocomial bloodstream infections following health care restructuring in Alberta between 1999 and 2005. Can J Infect Dis Med Microbiol 2010;21(1):e1-e5.

OBJECTIVE: A previous study at the University of Alberta Hospital/ Stollery Children's Hospital in Edmonton, Alberta, revealed an increase in hospital-acquired bloodstream infection (BSI) rates associated with an increase in patient acuity during a period of public health care delivery restructuring between 1993 and 1996. The present study assessed trends in BSIs since the end of the restructuring.

DESIGN: Prospective surveillance for BSIs was performed using Centers for Disease Control and Prevention (USA) criteria for infection. BSI cases between January 1, 1999, and December 31, 2005, were reviewed. Available measures of patient volumes, acuity and BSI risk factors between 1999 and 2005 were also reviewed from hospital records.

SETTING: The University of Alberta Hospital/Stollery Children's Hospital (617 adult and 139 pediatric beds, respectively).

PATIENTS: All pediatric and adult patients admitted during the above-specified period with one or more episodes of BSIs.

RESULTS: There was a significant overall decline in the BSI number and rate over the study period between 1999 and 2005. The downward trend was widespread, involving both adult and pediatric populations, as well as primary and secondary BSIs. During this period, the number of hospital-wide and intensive care unit admissions, intensive care unit central venous catheter-days, total parenteral nutrition days and number of solid-organ transplants were either unchanged or increased. Grampositive bacterial causes of BSIs showed significant downward trends, but Gram-negative bacterial and fungal etiologies were unchanged. CONCLUSIONS: These data imply that, over time, hospitals can gradually adjust to changing patient care circumstances and, in this example, control infectious complications of health care delivery.

Key Words: Bloodstream infections; BSI; Health care delivery; Health care restructuring; Infection control; Trends

【ospital-acquired (nosocomial) infections are the most com1 mon complication of health care delivery (1). Bloodstream infections (BSIs) are especially serious, and, because they are readily detectable through prospective surveillance, they are useful markers of long-term trends in infection rates. Occurrences of health care-acquired infections are known to be sensitive to processes of care (2,3). The 1993 to 1996 restructuring era of public health care delivery in the province of Alberta involved a dramatic budgetary funding cut for existing health care services, and a significant shifting of certain types of patients from acute tertiary hospitals to community-based hospital settings. This also resulted in a significant reduction in the operational budget of the University of Alberta Hospital and the Stollery Children's Hospital (located within the University of Alberta Hospital) in

\section{Les tendances d'infections hématogènes nosocomiales après la restructuration des soins de santé en Alberta entre 1999 et 2005} OBJECTIF : Une étude antérieure menée à l'University of Alberta Hospital
et au Stollery Children's Hospital d'Edmonton, en Alberta, a révélé une
augmentation du taux d'infections hématogènes nosocomiales (IHN)
associée à une augmentation de l'acuité des patients pendant la période de
restructuration de la prestation des soins entre 1993 et 1996. La présente
étude visait à évaluer les tendances d'IHN depuis la fin de la
restructuration.

MÉTHODOLOGIE : Les auteurs ont procédé à la surveillance prospective des IHN au moyen des critères d'infection des Centers for Disease Control and Prevention des États-Unis. Ils ont examiné les cas d'IHN entre le $1^{\text {er }}$ janvier 1999 et le 31 décembre 2005. Ils ont également examiné les mesures disponibles à l'égard des volumes de patients, de l'acuité et des facteurs de risque d'IHN entre 1999 et 2005 à partir des dossiers hospitaliers.

LIEU : L'University of Alberta Hospital et le Stollery Children's Hospital (617 lits pour adultes et 139 lits pour enfants, respectivement).

PATIENTS : Tous les enfants et les adultes hospitalisés pendant la période précisée plus haut en raison d'au moins un épisode d'IHN.

RÉSULTATS : On a constaté un fléchissement global significatif du nombre et du taux d'IHN pendant la période de l'étude, entre 1999 et 2005. Cette tendance à la baisse était généralisée, tant au sein de la population d'adultes que d'enfants et des IHN primaires que secondaires. Pendant cette période, le nombre d'hospitalisations dans les divers départements et aux soins intensifs, les jours-cathéter veineux central aux soins intensifs, les journées sous alimentation parentérale totale et le nombre de greffes d'organes étaient soit inchangés, soit à la hausse. Les causes d'IHN à bactéries Gram positif ont beaucoup baissé, mais les étiologies fongiques et de bactéries Gram négatif sont demeurées inchangées.

CONCLUSIONS : Selon ces données, au fil du temps, les hôpitaux peuvent graduellement s'adapter aux modifications à la situation des soins aux patients et, dans cet exemple, aux complications infectieuses de contrôle pour la prestation des soins.

Edmonton, Alberta, and a marked concomitant increase in patient acuity and in primary and secondary BSI rates (4).

In the present follow-up study, we sought to analyze the trends of both hospital activity and patient acuity as well as BSIs during the subsequent seven years following the previous report (4).

\section{PATIENTS AND METHODS}

The present study was conducted at the University of Alberta Hospital and Stollery Children's Hospital - a hospital complex with 139 pediatric and 617 adult beds, with over 700,000 patients treated annually from western and northern Canada. This is the principal teaching facility of the University of Alberta's Faculty of Medicine and Dentistry. A full range of diagnostic and treatment services are offered including cardiac surgery, neurosurgery and

${ }^{1}$ Division of Infectious Diseases, Department of Medicine, University of Alberta Hospital; ${ }^{2}$ Division of Infectious Diseases, Department of Pediatrics, Stollery Children's Hospital, Edmonton, Alberta

Correspondence: Dr Mao-Cheng Lee, Division of Infectious Diseases, Department of Medicine, University of Alberta Hospital, \#200, 10150-102 Street, Edmonton, Alberta T5J 5E2. Telephone 780-451-3702, fax 780-454-2845, e-mail Mao-Cheng.Lee@albertahealthservices.ca 
TABLE 1

Hospital volume and activity by year (1999 to 2005)

\begin{tabular}{|c|c|c|c|c|c|c|c|}
\hline & 1999 & 2000 & 2001 & 2002 & 2003 & 2004 & 2005 \\
\hline \multicolumn{8}{|l|}{ Admissions, $n$} \\
\hline Total & 31,186 & 30,155 & 30,327 & 31,724 & 33,285 & 34,826 & 35,986 \\
\hline Adult & 26,701 & 25,592 & 25,376 & 25,634 & 26,569 & 28,097 & 29,050 \\
\hline Pediatric & 4485 & 4563 & 4951 & 6090 & 6716 & 6729 & 6936 \\
\hline \multicolumn{8}{|l|}{ Patient-days, n } \\
\hline Total & 237,145 & 226,365 & 251,350 & 251,530 & 266,607 & 276,443 & 281,259 \\
\hline Adult & 205,092 & 202,880 & 221,943 & 217,151 & 228,600 & 236,397 & 241,829 \\
\hline Pediatric & 32,053 & 23,485 & 29,407 & 34,379 & 38,007 & 40,046 & 39,430 \\
\hline \multicolumn{8}{|l|}{ ICU admissions, $n$} \\
\hline Total & 921 & 951 & 822 & 611 & 814 & 793 & 979 \\
\hline Adult & 677 & 612 & 579 & 422 & 603 & 573 & 748 \\
\hline Pediatric & 244 & 339 & 243 & 189 & 211 & 220 & 231 \\
\hline \multicolumn{8}{|l|}{ ICU patient-days, n } \\
\hline Total & 29,655 & 25,791 & 27,212 & 29,373 & 30,449 & 32,396 & 32,877 \\
\hline Adult & 26,878 & 22,775 & 23,849 & 25,308 & 26,250 & 27,776 & 28,389 \\
\hline Pediatric & 2777 & 3016 & 3363 & 4065 & 4199 & 4620 & 4488 \\
\hline \multicolumn{8}{|l|}{ ICU central venous catheter line-days, $n$} \\
\hline Total & 15,293 & 15,273 & 13,260 & 17,976 & 18,806 & 20,275 & 22,276 \\
\hline Adult & 10,824 & 11,618 & 9140 & 13,438 & 14,542 & 15,385 & 16,209 \\
\hline Pediatric & 4469 & 3655 & 4120 & 4538 & 4264 & 4890 & 6067 \\
\hline \multicolumn{8}{|l|}{ Total parenteral nutrition days, $\mathrm{n}$} \\
\hline Total & 17,352 & 14,883 & 14,634 & 16,003 & 15,664 & 17,177 & 17,867 \\
\hline Adult & 11,618 & 10,688 & 10,126 & 10,606 & 10,480 & 11,251 & 11,733 \\
\hline Pediatric & 5734 & 4195 & 4508 & 5397 & 5184 & 5926 & 6134 \\
\hline Transplant procedures (solid organ), $n$ & 181 & 209 & 228 & 235 & 191 & 221 & 269 \\
\hline
\end{tabular}

ICU Intensive care unit

neurology, general surgery, internal medicine and its subspecialty services, renal dialysis, emergency and solid-organ transplant (SOT) for both the pediatric and the adult population. Obstetrics/ gynecology and ophthalmology services are not included. There are seven intensive care units ([ICUs] - coronary, adult cardiac surgery, adult neurosurgery, adult medical-surgical, burns, pediatric and neonatal), which make up $14.4 \%$ of rated beds. No change in services provided occurred during the study period.

\section{Hospital volume and acuity}

To assess the trends in hospital patient care volume, the number of annual patient-days (overall) and admissions in both hospitals and in the seven ICUs were obtained. To assess changes in the prevalence of risk factors for BSI, facility-wide days-of-use of total parenteral nutrition (TPN) supplied by the hospital pharmacy $(5,6)$, central venous catheter (CVC) days-of-use by ICUs (excluding neonatal ICUs) (7-9) and annual number of all on-site SOTs (kidney, liver, heart, lung and heart-lung) were determined. Data on the number of hemodialysis runs performed annually by the hemodialysis unit, the extent of mechanical ventilation use in the ICUs or CVC days-of-use outside of the ICUs for the period of the current study were not available for use as additional indicators of acuity.

\section{Hospital-acquired BSIs and rates}

Prospective surveillance for hospital-acquired BSIs in all units has been performed in the facility since 1986 (except 1998) by prospective monitoring of clinical microbiology laboratory reports as well as review of patient charts by the hospitals' infection control practitioners, as previously described $(10,11)$. The Centers for Disease Control and Prevention (USA) criteria for infection are used $(12,13)$. Infection rates are calculated using patient-days, patient admissions and catheter-days as denominators where applicable - all supplied by the hospitals' information systems department and the respective ICUs. ICU CVC-associated BSI rates were calculated using CVC line-days as denominators, which were supplied by the ICU departments $(9,14)$. Primary BSIs are attributable to CVCs only, which may include a small number of transient in-ICU hemodialysis and peripherally inserted central catheter lines, and are exclusive of all peripheral lines. Secondary BSIs are attributable to all other body sources and exclusive of all intravenous devices - central or peripheral. Infections and infection rates occurring in the seven years (1999 to 2005) following the end of the 1993 to 1996 Alberta health care restructuring were analyzed.

\section{Statistical calculations}

To detect any significant monotonic, linear temporal trends in the rates, a nonparametric Mann-Kendall test (15) was performed. In the Mann-Kendall test, a negative (positive) value of $S$, where $S$ is the Kendall trend score, indicates a downward (upward) trend. The magnitude of the linear trend in terms of slope Q was then estimated using a nonparametric Sen's method (15). P value shows statistical significance of the trend analysis. The calculations were performed using an Excel (Microsoft Corporation, USA) macrotemplate MAKESENS (Mann-Kendall test for trend and Sen's slope estimates [16]).

\section{RESULTS}

Hospital volume and acuity (Table 1 )

Over the 10 years following the restructuring era, there was a steady rise in the number of total admissions at the University 


\begin{tabular}{|c|c|c|c|c|c|c|c|c|c|}
\hline & 1999 & 2000 & 2001 & 2002 & 2003 & 2004 & 2005 & Total & $\mathbf{P}$ \\
\hline \multicolumn{10}{|l|}{ All primary BSI } \\
\hline Total number of ICU CVC lines infected & 63 & 75 & 51 & 83 & 75 & 65 & 63 & 475 & - \\
\hline Total central line-days & 15,293 & 15,273 & 13,260 & 17,976 & 18,806 & 20,275 & 22,276 & 123,159 & - \\
\hline Rate per 1000 catheter-days & 4.12 & 4.91 & 3.85 & 4.62 & 3.99 & 3.21 & 2.83 & 3.86 & $0.033^{*}$ \\
\hline \multicolumn{10}{|l|}{ Pediatric } \\
\hline Total number of ICU CVC lines infected & 17 & 15 & 14 & 23 & 18 & 21 & 12 & 120 & - \\
\hline Total central line-days & 4469 & 3655 & 4120 & 4538 & 4264 & 4890 & 6067 & 32,003 & - \\
\hline Rate per 1000 catheter-days & 3.80 & 4.10 & 3.40 & 5.07 & 4.22 & 4.29 & 1.98 & 3.75 & 0.50 \\
\hline \multicolumn{10}{|l|}{ Adult } \\
\hline Total number of ICU CVC lines infected & 46 & 60 & 37 & 60 & 57 & 44 & 51 & 355 & - \\
\hline Total central line-days & 10,824 & 11,618 & 9,140 & 13,438 & 14,542 & 15,385 & 16,209 & 91,156 & - \\
\hline Rate per 1000 catheter-days & 4.25 & 5.16 & 4.05 & 4.46 & 3.92 & 2.86 & 3.15 & 3.89 & $0.033^{*}$ \\
\hline
\end{tabular}

'Total central line-days' and 'rate per 1000 catheter-days' are both based on intensive care unit (ICU) central venous catheter (CVC) days only. P value assesses trends in rates. ${ }^{*} P<0.05$

TABLE 3

Hospital-acquired secondary bloodstream infections (BSIs) and rates (1999 to 2005)

\begin{tabular}{|c|c|c|c|c|c|c|c|c|c|c|c|}
\hline & 1999 & 2000 & 2001 & 2002 & 2003 & 2004 & 2005 & Total & $\mathrm{S}$ & Q & $\mathbf{P}$ \\
\hline \multicolumn{12}{|l|}{ All secondary BSI } \\
\hline Total BSIs, n & 181 & 213 & 180 & 169 & 153 & 172 & 172 & 1240 & & & \\
\hline Total patient-days & 237,145 & 226,365 & 251,350 & 251,530 & 266,607 & 276,443 & 281,259 & $1,790,699$ & & & \\
\hline Rate per 1000 patient-days & 0.76 & 0.94 & 0.72 & 0.67 & 0.57 & 0.62 & 0.61 & 0.69 & -15 & -0.03 & $0.016^{*}$ \\
\hline \multicolumn{12}{|l|}{ Pediatric } \\
\hline Total BSIs, n & 29 & 34 & 27 & 38 & 28 & 36 & 19 & 211 & & & \\
\hline Total patient-days & 32,053 & 23,485 & 29,407 & 34,379 & 38,007 & 40,046 & 39,430 & 236,807 & & & \\
\hline Rate per 1000 patient-days & 0.90 & 1.45 & 0.92 & 1.11 & 0.74 & 0.90 & 0.48 & 0.89 & -11 & -0.10 & 0.060 \\
\hline \multicolumn{12}{|l|}{ Adult } \\
\hline Total BSIs, n & 152 & 179 & 153 & 131 & 125 & 136 & 153 & 1029 & & & \\
\hline Total patient-days & 205,092 & 202,880 & 221,943 & 217,151 & 228,600 & 236,397 & 241,829 & $1,553,892$ & & & \\
\hline Rate per 1000 patient-days & 0.74 & 0.88 & 0.69 & 0.60 & 0.55 & 0.58 & 0.63 & 0.66 & -11 & -0.04 & 0.060 \\
\hline \multicolumn{12}{|c|}{ Secondary source BSI adult rates } \\
\hline \multicolumn{12}{|l|}{ Urinary tract infection source } \\
\hline Total BSIs, n & 30 & 18 & 15 & 28 & 22 & 27 & 34 & 174 & & & \\
\hline Rate per 1000 patient-days & 0.15 & 0.09 & 0.07 & 0.13 & 0.10 & 0.11 & 0.14 & 0.11 & 3 & 0.004 & 0.728 \\
\hline \multicolumn{12}{|l|}{ Pneumonia source } \\
\hline Total BSIs, n & 37 & 55 & 38 & 38 & 38 & 27 & 31 & 264 & & & \\
\hline Rate per 1000 patient-days & 0.18 & 0.27 & 0.17 & 0.17 & 0.17 & 0.11 & 0.13 & 0.17 & -15 & -0.013 & $0.017^{*}$ \\
\hline \multicolumn{12}{|l|}{ Superficial skin infection source } \\
\hline Total BSIs, n & 2 & 3 & 1 & 4 & 2 & 2 & 7 & 21 & & & \\
\hline Rate per 1000 patient-days & 0.010 & 0.015 & 0.005 & 0.018 & 0.009 & 0.008 & 0.029 & 0.014 & 3 & 0.002 & 0.728 \\
\hline
\end{tabular}

$P$ value assesses trends in rates. ${ }^{\star} P<0.05$

of Alberta/Stollery Children's Hospitals, in proportion with an $18.5 \%$ population growth in the city of Edmonton. Incidence rates of new admissions per unit of patient time at risk were comparable through time (data not shown). This was also paralleled by an increasing number of patient-days spent in the hospital and in the ICUs annually. Additionally, within the hospital's five adult and one pediatric ICUs (neonatal ICU excluded), the annual use of CVCs showed considerable upward trend over the study period, with a lesser nonsignificant upward trend observed in the adults' and pediatrics' inpatient TPN use. The number of SOTs (both children and adult) at the site rose from 181 cases in 1999 to 269 cases in 2005.

Hospital-acquired primary BSIs and rates (Table 2)

From 1999 to 2005, there were a total of 475 episodes of ICU. acquired primary BSIs, which occur largely as a complication of intravascular catherization. A steady and significant downward trend was observed in the rate of primary BSIs in the adult population $(\mathrm{S}=-13 ; \mathrm{P}=0.033)$, which fell from 4.25 episodes per 1000 catheter-days in 1999 to 3.15 episodes per 1000 catheterdays by 2005 . The overall trend within the pediatric population remained largely unchanged over our study period despite a seeming nonsignificant upward trend peaking in 2002.

Hospital-acquired secondary BSIs and rates (Table 3)

Although the rate of secondary BSIs in the adult and pediatric groups of patients each showed a positive downward trend during this study period $(\mathrm{S}=-11 ; \mathrm{P}=0.06$ for both; $\mathrm{Q}$ slope $=-0.04$ and -0.10 , respectively), they did not reach statistical significance individually. The combined rate resulted, however, in a significant downward trend overall $(S=-15 ; Q=-0.03$; $\mathrm{P}=0.016)$. The rates of pneumonia-related BSI displayed a significant reduction over the duration of the study period $(\mathrm{S}=-15 ; \mathrm{P}=0.017)$. 
TABLE 4

Blood stream infections in adult population: Trends by pathogens per 1000 admissions

\begin{tabular}{|c|c|c|c|c|c|c|c|c|c|c|c|}
\hline Pathogens & 1999 & 2000 & 2001 & 2002 & 2003 & 2004 & 2005 & Mean & s & Q & $\mathbf{P}$ \\
\hline \multicolumn{12}{|l|}{ Candida species } \\
\hline Total, $\mathrm{n}$ & 29 & 25 & 23 & 17 & 22 & 16 & 29 & 23 & & & \\
\hline Rate per 1000 patient-days & 1.09 & 0.98 & 0.91 & 0.66 & 0.83 & 0.57 & 1.00 & 0.86 & -11 & -0.011 & 0.064 \\
\hline Total, $\mathrm{n}$ & 135 & 105 & 130 & 117 & 108 & 123 & 105 & 118 & & & \\
\hline Rate per 1000 patient-days & 5.06 & 4.10 & 5.12 & 4.56 & 4.06 & 4.38 & 3.61 & 4.40 & -13 & -0.035 & $0.030^{*}$ \\
\hline Rate per 1000 patient-days & 2.51 & 2.58 & 2.01 & 1.83 & 1.73 & 1.85 & 1.89 & 2.05 & -11 & -0.015 & 0.064 \\
\hline \multicolumn{12}{|l|}{ Staphylococcus aureus } \\
\hline Total, n & 81 & 75 & 73 & 70 & 44 & 56 & 51 & 64 & & & \\
\hline Rate per 1000 patient-days & 3.03 & 2.93 & 2.88 & 2.73 & 1.66 & 1.99 & 1.76 & 2.41 & -17 & -0.031 & $0.007^{*}$ \\
\hline \multicolumn{12}{|l|}{ Pseudomonas species } \\
\hline Total, $\mathrm{n}$ & 17 & 20 & 18 & 16 & 15 & 12 & 19 & 17 & & & \\
\hline Rate per 1000 patient-days & 0.97 & 0.82 & 0.91 & 1.09 & 0.75 & 0.89 & 0.96 & 0.91 & 1 & 0.0001 & 0.50 \\
\hline \multicolumn{12}{|l|}{ Others } \\
\hline Total, $\mathrm{n}$ & 3 & 5 & 0 & 0 & 4 & 3 & 3 & 3 & & & \\
\hline Rate per 1000 patient-days & 0.11 & 0.20 & 0.00 & 0.00 & 0.15 & 0.11 & 0.10 & 0.10 & -4 & -0.0004 & 0.319 \\
\hline Total adult patient admission, $\mathrm{n}$ & 26,701 & 25,592 & 25,376 & 25,634 & 26,569 & 28,097 & 29,050 & 26,717 & & & \\
\hline
\end{tabular}

$P$ assesses trends in rates. ${ }^{*} P<0.05$

Hospital-acquired BSIs by organisms (Table 4)

Table 4 shows organism-specific trends for the seven most common microorganisms implicated in BSIs reported in the hospital. Between 1999 and 2005, a steady decline in Gram-positive organisms as agents of BSIs was observed. Specifically, coagulasenegative Staphylococcus $(\mathrm{Q}=-0.035)$, Enterococcus species $(\mathrm{Q}=-0.015)$ and Staphylococcus aureus $(\mathrm{Q}=-0.031)$ all showed downward trends and, with the exception of Enterococcus species, all reached statistical significance (Table 4). Pseudomonas species $(\mathrm{Q}=-0.0063)$ infection rates also showed a downward trend. The rate of infection involving other BSI-implicated microorganisms, including Candida species, Corynebacterium species, anaerobes and all other Gram-negative organisms, remained unchanged over this time.

\section{DISCUSSION}

In the present study, we have found that the overall combined BSI rates, both primary and secondary, among adult and pediatric populations served by the University of Alberta Hospital/ Stollery Children's Hospital fell significantly following the end of the restructuring era between 1993 and 1996. By 2005, the hospitals' BSI rate had returned to the baseline rate seen immediately before the restructuring era (analysis data not shown). The fall in the primary BSIs, particularly among adults and occurring in most circumstances as a complication of intravascular catherization, was reflected by the marked decline in Gram-positive bacteremia, and $S$ aureus in particular, while bacteremia involving other common pathogens remained mostly unchanged. Over the same period, the hospital's patient volume and acuity, as marked by patient admission volumes, length of stay (expressed in patient-days), and BSI risk factors such as CVC use, TPN use and number of SOTs, increased substantially.
Our current findings are counter to the trends observed during the restructuring period in Alberta (1993 to 1996), which saw a period of rapid health care downsizing and shifting care and resources from acute tertiary hospitals to community-based hospital settings (4). During that era, bed numbers at the University of Alberta Hospital/Stollery Children's Hospital fell by $10 \%$, and volumes declined following a $19 \%$ drop in the annual number of admissions and a 17\% drop in the annual patient-days parameter. Acuity soared concomitantly. Markers of hospital acuity such as ICU use of CVCs, number of TPN days, and number of hemodialysis runs reflected that trend, with increases seen at $41 \%, 25 \%$ and $9 \%$, respectively (4). Concurrently, some services within tertiary centres saw a marked increase in patient-days (neurosurgery 49\%, nephrology 30\%, orthopedic surgery $24 \%$ and general surgery $16 \%$ ). During this same period, hospital-acquired BSIs saw a dramatic increase such that toward the end of the restructuring period, there was an annual $31 \%$ increase in the number of hospital-acquired BSIs and a $60 \%$ increase in BSI rate compared with that observed in the prerestructuring era.

In spite of the soaring of facility volumes and acuity since the end of the restructuring era, the present study shows that BSI rates have steadily declined in the 10 years that followed to near prerestructuring baseline. During the same period, Census Canada data revealed that the city of Edmonton saw a steady population growth of $18.5 \%, 8.1 \%$ of which occurred before the beginning of the current study. Such concomitant population growth before and during our study may have accounted in part for the increased hospital activity and volume we have observed. In contrast, it is unlikely that a technological improvement in care is solely responsible for the decline in BSI rates. Improved care of CVC lines and the introduction of antibiotic-impregnated catheters (which 
occurred midpoint of the study period) may have accounted for some of the observed trend, especially in the decline of the primary BSI rate. However, introduction of antimicrobialimpregnated catheters would be expected to have a singlestep effect on BSI rate rather than a gradual downward trend. No systematic institution-wide process to improve the quality of catheter care was implemented during the study period. Furthermore, the reductions seen were widespread, involving pediatric and adult patient groups, and secondary and primary BSIs. Thus, a single change in the process of care is unlikely to have resulted in such widespread and progressive decline in BSI rates. Rather, the most likely explanation for our observed BSI rate decline, considering all observations gathered, would be that a collection of potentially heterogeneous health care process improvements occurred within the University of Alberta Hospital/Stollery Children's Hospital during our study period. Examples of such care processes would include improved CVC care and use, mouth care, skin antisepsis and hand hygiene, among others.

Unlike BSIs involving Gram-positive organisms, BSIs with Pseudomonas aeruginosa very infrequently involve CVCs as primary sources $(17,18)$. Rather, bacteremia with Pseudomonas aeruginosa is often secondary, originating most commonly from primary sites such as the respiratory system (eg, ventilator-associated pneumonia), and, to a lesser extent, urinary and surgical wound sites (17). This offers a plausible explanation for the concurrent decline in the rates of Pseudomonas aeruginosa BSIs and that of pneumonia-derived secondary BSI source in the present study. Although multifactorial in cause, enhanced quality of care through improved oral hygiene and ICU-assisted respiratory support would invariably account for the observed reduction in pneumonia rates at our site over the study period.

\section{REFERENCES}

1. Leape LL, Brennan TA, Laird N, et al. The nature of adverse events in hospitalized patients. Results of the Harvard Medical Practice Study II. N Engl J Med 1991;324:377-84.

2. Siegel J, Rhinehart E, Jackson M, Chiarello L; the Healthcare Infection Control Practices Advisory Committee. Guideline for Isolation Precautions: Preventing Transmission of Infectious Agents in Healthcare Settings. Atlanta, Georgia: Centers for Disease Control and Prevention, 2007.

3. Pittet D, Donaldson L. Challenging the world: Patient safety and health care-associated infection. Int J Qual Health Care 2006; 18:4-8.

4. Taylor GD, McKenzie M, Kirkland T, Buchanan-Chell M, Wiens R. The impact of health care restructuring on nosocomially acquired blood stream infections. Can J Infect Dis 2000;11:29-32.

5. Buchman AL. Catheter-related complications of total parenteral nutrition. Am J Gastroenterol 2007;102(Suppl 1):S97-S101.

6. Marra AR, Opilla M, Edmond MB, Kirby DF. Epidemiology of bloodstream infections in patients receiving long-term total parenteral nutrition. J Clin Gastroenterol 2007;41:19-28.

7. Fridkin SK, Welbel SF, Weinstein RA. Magnitude and prevention of nosocomial infections in the intensive care unit. Infect Dis Clin North Am 1997;11:479-96.

8. Gastmeier P, Sohr D, Geffers C, Behnke M, Rüden H. Risk factors for death due to nosocomial infection in intensive care unit patients: Findings from the Krankenhaus Infections Surveillance System. Infect Control Hosp Epidemiol 2007;28:466-72.

9. Jarvis WR, Edwards JR, Culver DH, et al. Nosocomial infection rates in adult and pediatric intensive care units in the United States. National Nosocomial Infections Surveillance System. Am J Med 1991;91(3B):185S-91S.
Thus, our data were most compatible with a gradual improvement in quality of care, returning BSI rates to the prerestructuring baseline. These findings are not surprising. As stated by Pittet and Donaldson (3) in their launch of the Global Patient Safety Challenge and WHO World Alliance for Patient Safety, adverse events in health care settings are not just a series of unconnected one-off incidents. Multiple observations have substantiated that institutional level factors of health care organizational culture, leadership, staff education and morale, and staffing levels are critical to controlling health care-associated infections $(2,19)$. Our data imply that over time, hospitals can gradually adjust to changing patient care circumstances and, in this example, control BSI rates as representing infectious complications of health care delivery.

ACKNOWLEDGEMENT: The authors thank the health care worker volunteers (physicians, nurses, health care allies) for their contribution to the present study, and Marilou HervasMalo at the EPICORE Centre (www.epicore.ualberta.ca) at the University of Alberta (Edmonton, Alberta) for her suggestions regarding statistical methods. The current study was presented in part at the 2007 Annual Meeting of the Association of Medical Microbiology and Infectious Diseases/Canadian Association for Clinical Microbiology and Infectious Diseases in Toronto, Ontario.

CONFLICT OF INTEREST AND FUNDING DISCLOSURE: None of the authors have any commercial associations or other arrangements (eg, financial compensation received, patient-licensing arrangements, potential to profit, stock ownership, etc) that may pose a conflict of interest in connection with the article.

10. Taylor GD, Buchanan-Chell M, Kirkland T, McKenzie M, Wiens R. Nosocomial Gram-negative bacteremia. Int J Infect Dis 1997;1:202-5.

11. Taylor GD, McKenzie M, Buchanan-Chell M, Caballo L, Chui L, Kowalewska-Grochowska K. Central venous catheters as a source of hemodialysis-related bacteremia. Infect Control Hosp Epidemiol 1998;19:643-6.

12. Garner JS, Jarvis WR, Emori TG, Horan TC, Hughes JM. CDC definitions for nosocomial infections, 1988. Am J Infect Control 1988;16:128-40.

13. Horan TC, Gaynes RP, Martone WJ, Jarvis WR, Emori TG. CDC definitions of nosocomial surgical site infections, 1992: A modification of CDC definitions of surgical wound infections. Am J Infect Control 1992;20:271-4.

14. Gaynes RP, Solomon S. Improving hospital-acquired infection rates: The CDC experience. Jt Comm J Qual Improv 1996;22:457-67.

15. Gilbert RO. Statistical methods for environmental pollution monitoring. New York: Van Nostrand Reinhold Co, 1987.

16. Salmi T, Määttä A, Anttila P, Ruoho-Airola T, Amnell T. Detecting Trends of Annual Values of Atmospheric Pollutants by the Mann-Kendall Test and Sen's Slope Estimates - The Excel Template Application MAKESENS. Helsinki: Finnish Meteorological Institute, 2002.

17. Sherertz RJ, Sarubbi FA. A three-year study of nosocomial infections associated with Pseudomonas aeruginosa. J Clin Microbiol $1983 ; 18: 160-4$

18. Tullu MS, Deshmukh CT, Baveja SM. Bacterial profile and antimicrobial susceptibility pattern in catheter related nosocomial infections. J Postgrad Med 1998;44:7-13.

19. World Alliance for Patient Safety. Global Patient Safety Challenge. Geneva, Switzerland: World Health Organization, 2005. 


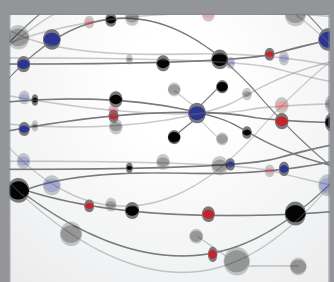

The Scientific World Journal
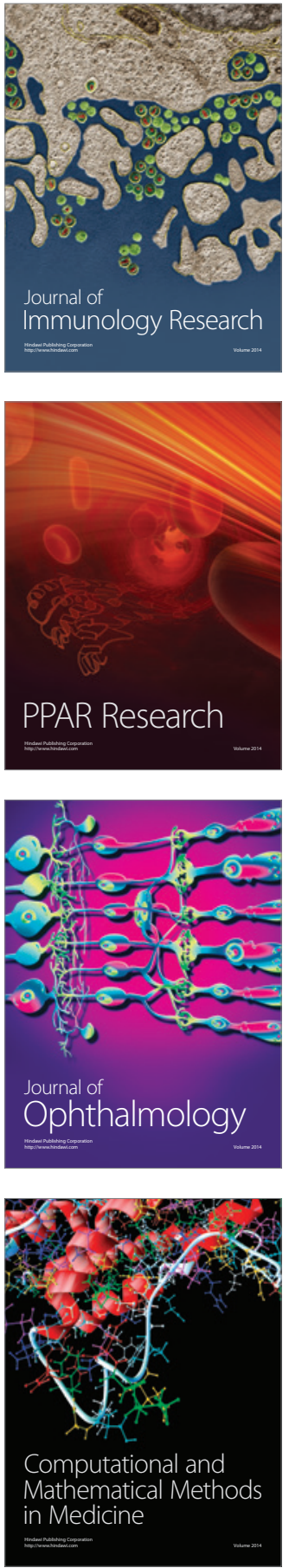

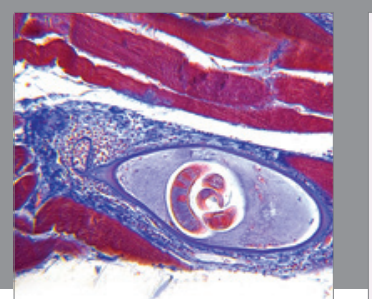

Gastroenterology Research and Practice

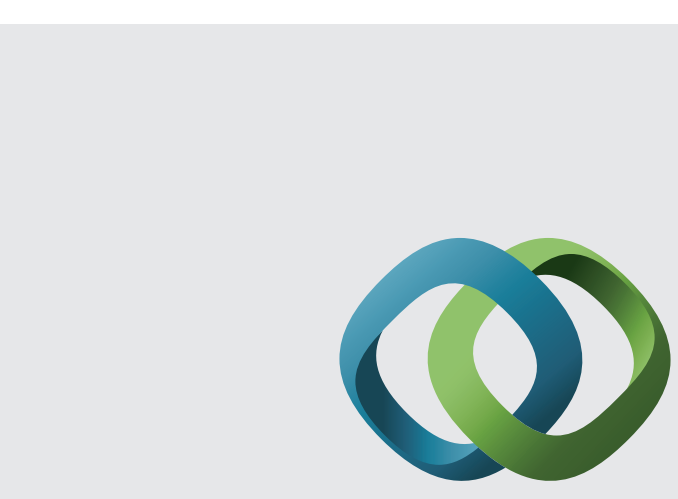

\section{Hindawi}

Submit your manuscripts at

http://www.hindawi.com
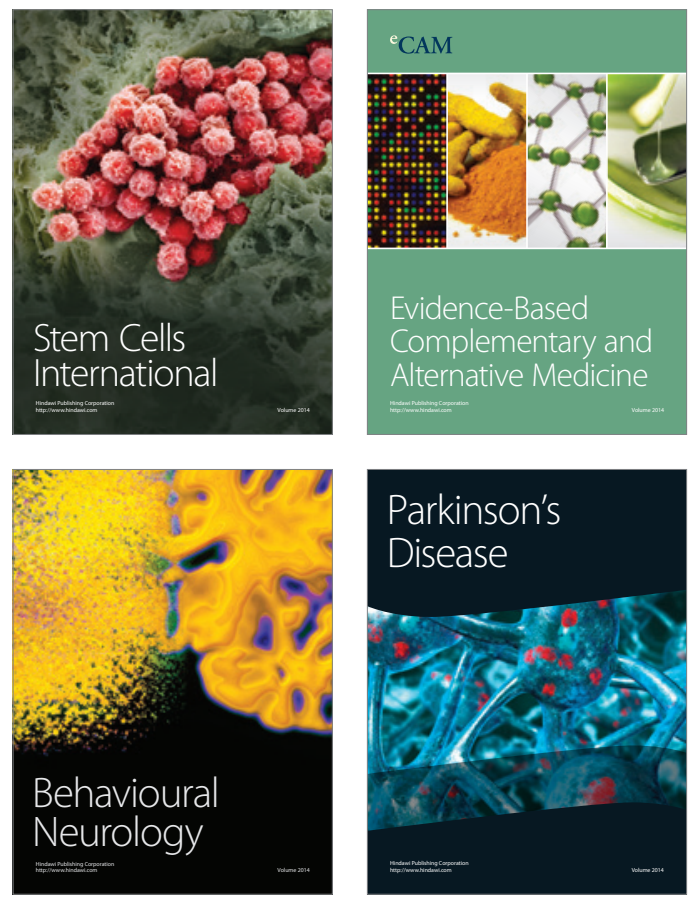
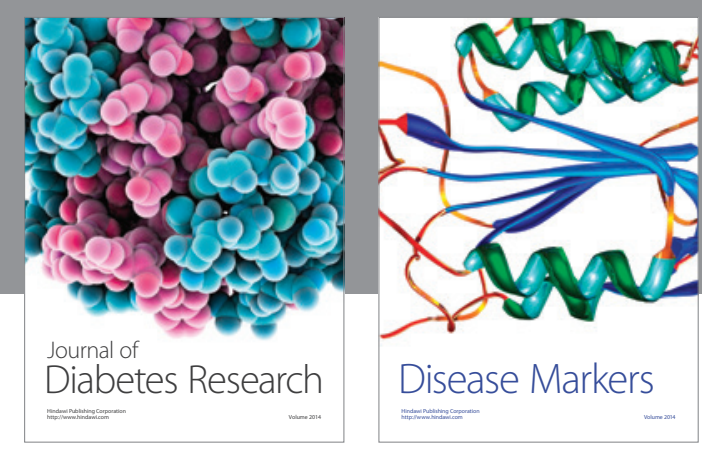

Disease Markers
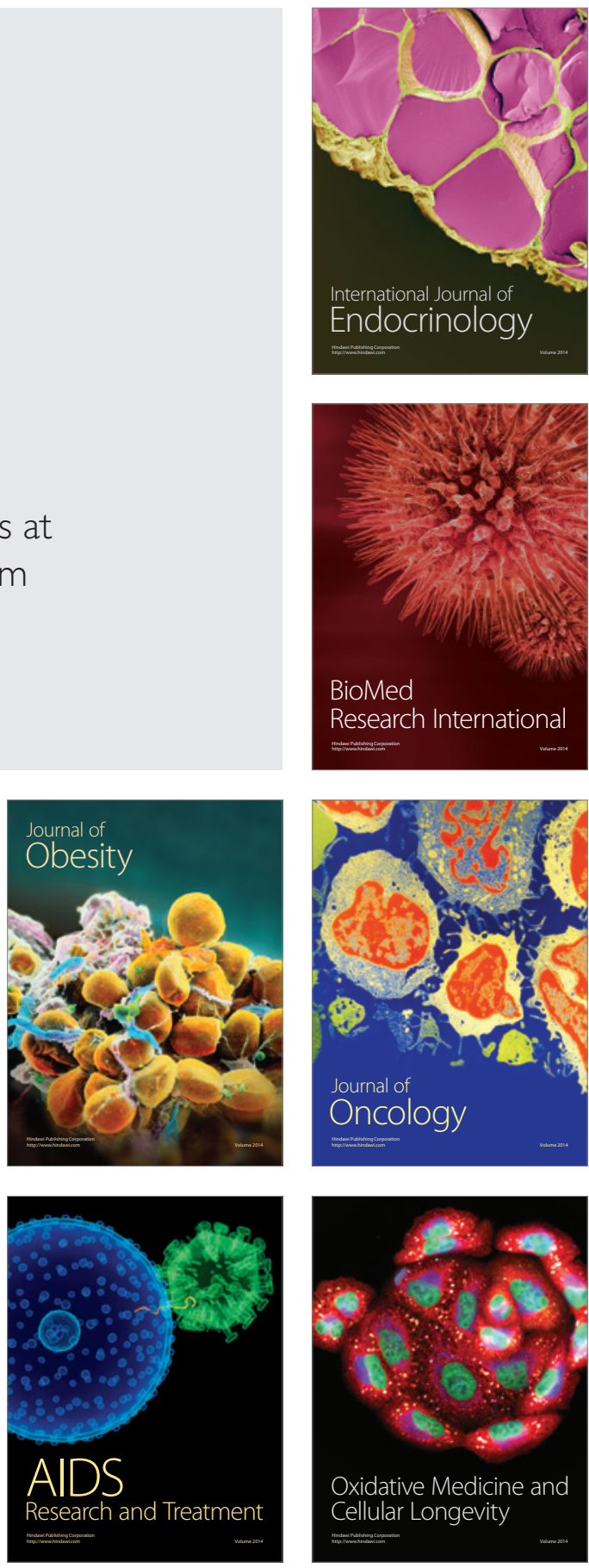